\title{
Beyond self-criticism and dependency: structural functioning of depressive patients and its treatment
}

\author{
Guillermo de la Parra, ${ }^{1}$ Paula Dagnino, ${ }^{1,2}$ Camila Valdés, ${ }^{3}$ Mariane Krause ${ }^{3}$ \\ ${ }^{1}$ Psychiatry Department, Pontificia Universidad Catolica de Chile, Santiago; ${ }^{2}$ Psychology Faculty, Universidad Gabriela Mistral, Santiago; \\ ${ }^{3}$ Psychology School, Pontificia Universidad Catolica de Chile, Santiago, Chile
}

\begin{abstract}
Van Praag states that the underlying psychic dysfunctions in psychopathology must be evaluated (and treated) in patient-centered treatments. In line with this idea, Blatt and colleagues propose the concept of self-critical (introjective) and dependent (anaclitic) functioning. The research program Millennium Initiative has studied self-critical and dependent functioning from different perspectives. The general aim of this paper is to share the results of the program that have contributed to clinical psychotherapeutic thinking. Its

Correspondence: Guillermo de la Parra, Pontificia Universidad Catolica de Chile, Vicuña Mackenna 4860, Macul, 7810000 Santiago, Chile.

E-mail: gdelaparra@uc.cl

Contributions: all of the authors contributed to the design of the work and the interpretation of data for the work, they also revised the work critically for important intellectual content and participated in the final approval of the version to be published, and ensured the integrity of the work.

Conflict of interest: the authors declare no potential conflict of interest.

Note: this work was presented partially at the 46th Annual International Meeting of the Society for Psychotherapy Research at Philadelphia, Pennsylvania, USA, June 24-27, 2015, entitled: Structural vulnerabilities in depressive experiences: what is at the base?

Acknowledgements: this study received support from the Millennium Scientific Initiative, Projects \#NS100018, from the Fund for Innovation and Competitiveness (FIC) of the Chilean Ministry of Economy, Development and Tourism, through the Millennium Scientific Initiative, Grant $\mathrm{N}^{\circ}$ IS130005, from CONICYT FONDECYT Postdoctorado $\mathrm{N}^{\circ} 3140402$ and from FONDECYT $\mathrm{N}^{\circ}$ 1130810. We thank Marcia Olhaberry, Eugenio Rodríguez, Jaime Silva, Nelson Valdés, Mariane Krause and all the patients and sub-

first specific aim is to summarize results reported elsewhere that support the predictive value of introjective and anaclitic functioning (Part I), while its second specific aim is to report original data that account for the structural functioning of personality underlying these two constructs (Part II). The results (Part I) show that self-critical functioning is associated with greater reactivity to stress (according to cortisol level in stress tasks) and less subjective awareness of stress, reduced performance in general tasks, and lower mentalization (errors in reading faces); also, patients with introjective (self-critical) depression receiving psychotherapy have more symptoms at onset, higher dropout rates, and poorer response to interventions than anaclitic (dependent) patients. Higher self-criticism was associated with higher depression scores; also, when comparing clinical and nonclinical samples, the latter showed less self-criticism. Therefore, self-critical functioning represents a challenge for researchers and clinicians. The evaluation of the structural functioning of personality showed (Part II) that self-critical functioning is associated with less integrated levels of structure and more depressive symptoms. This functioning is underlain by vulnerabilities in the abilities regulating object relationships and attachments to internal objects. Dependent functioning is associated with vulnerabilities in self-perception, self-regulation, and attachments to external objects. The psychotherapeutic implications of these results are discussed, paying special attention to aspects connected with structure-oriented psychotherapy.
\end{abstract} jects that participated in the studies. Finally, to the Society for Psychotherapy Research for being a relevant research network.

Citation: de la Parra, G., Dagnino, P., Valdés, C., \& Krause, M. (2017). Beyond self-criticism and dependency: structural functioning of depressive patients and its treatment. Research in Psychotherapy: Psychopathology, Process and Outcome, 20(1), 43-52. doi: 10.4081/ripppo.2017.236

Received for publication: 4 November 2016. Accepted for publication: 28 February 2017.

This work is licensed under a Creative Commons Attribution NonCommercial 4.0 License (CC BY-NC 4.0).

CCopyright G. de la Parra et al., 2017

Licensee PAGEPress, Italy

Research in Psychotherapy:

Psychopathology, Process and Outcome 2017; 20:43-52

doi:10.4081/ripppo.2017.236
Key words: Self-critical and dependent functioning; Personality structure; Self-criticism; Structure oriented psychotherapy.

\section{Introduction}

Thomae's and Kächele's (1987) clinical intuitions, which suggested an adaptive indication that meant that the therapist must adapt his/her technique and strategy to the patient's internal (diagnosis, functioning, personal resources, disease model, among other aspects) and external context (external reality that hinders or facilitates therapy), along with the scientific evidence accumulated in both the 
biological and the psychotherapeutic fields, make it difficult nowadays to hold the notion that there is a one-to-one correspondence between treatments and diagnostic categories.

This is also the case in the biological sphere of depression, where the coexistence of several (biological) explanatory theories - psychosocial stress and stress hormones, monoamines, neuroimages, the neurotrophic hypothesis, glutamatergic and gabaergic neurotransmission, and circadian rhythms - makes it impossible to advance a unified hypothesis for this disease (Hasler, 2010); therefore, as each theory applies only to some patients, treatments must be adapted to them. For Hasler (2010), we must advance towards a personalized medicine that has the potential to individually tailor interventions and to open up new pathways in the evaluation of novel therapeutic approaches (P.5). More specifically, van Praag (2010) refers to the dysfunctions that underlie psychopathological symptoms and mentions that it is these dysfunctions which should be treated with specific medications or particular psychotherapeutic measures.

From a psychological perspective, the decision to associate treatments with specific diagnostic and symptomatological categories has been forcefully challenged (for example, Laska, Gurman \& Wampold, 2014; Wampold, 2001). In addition, a person-centered approach has been proposed as an alternative to the symptom-centered approach by Blatt and colleagues (Blatt \& Luyten, 2009a, 2009b; Luyten \& Blatt, 2007), who see depressive pathology as the product of disruptions in the normal course of two key developmental tasks: self-definition (separation) and relatedness (attachment) (Blatt \& Luyten, 2009a, $2009 \mathrm{~b}$ ). The preponderance of these tasks is believed to result in two personality styles and two forms of depressive disease labeled introjective (self-definition) and anaclitic (relatedness) (Blatt, 1992, 2004; Blatt \& Luyten, 2009a, 2009b; Blatt, Quinlan, Chevron, McDonald, \& Zuroff, 1982; Blatt \& Shahar, 2003; Blatt \& Shichman, 1983; Blatt \& Zuroff, 1992).

For a comparison between anaclitic (dependent) and introjective (self critical) functioning, see Table 1 (based on Blatt, 1992, 2004; Blatt \& Luyten, 2009a, 2009b; Blatt \& Maroudas, 1992; Blatt et al., 1982; Blatt \& Shahar, 2003; Blatt \& Shichman, 1983; Blatt \& Zuroff, 1992; Layne, Porcelli, Shahar, 2006).

The self-critical (introjective) and/or dependent (anaclitic) types of functioning have been adequately assessed with the Depressive Experience Questionnaire (DEQ; Blatt, D'Affliti \& Quinlan, 1976; Blatt, Zohar, Quinlan, Zuroff, \& Mongrain, 1995; Zuroff, Quinlan, \& Blatt, 1990), which will be described in a later section.

Looking at the patient from the point of view of his/her functioning is absolutely in line with the notion of providing adaptive, patient-centered treatment.

This perspective is shared by the Operationalized Psychodynamic Diagnosis System (OPD-2, OPD Task Force, 2008). The OPD-2 system comprises 5 axes: (I) experience of illness and prerequisites for treatment, (II) interpersonal relations, (III) conflict, (IV) structure, and (V) mental and psychosomatic disorders. Axes II, III, and IV yield a personalized psychodynamic diagnosis that makes it possible to define the foci to be worked on in therapy and provide therapeutic strategies tailored to the patient. The OPD system defines structure as the way the self shapes itself, and functions, in relation to others (OPD Task Force, 2008, P.

Table 1. Comparison of anaclitic (dependent) and introjective (self critical) functioning.

\begin{tabular}{|c|c|c|}
\hline & Anaclitic & Introjective \\
\hline Principal task & Relatedness & Self definition \\
\hline Self & $\begin{array}{c}\text { Is defined predominantly in terms of the quality } \\
\text { of interpersonal relations }\end{array}$ & $\begin{array}{c}\text { Is defined through autonomy, control, independence, } \\
\text { and through a self-esteem based on recognition, } \\
\text { respect, and being admired }\end{array}$ \\
\hline Relation with others I & Intense yearning to be loved, protected and nurtured & $\begin{array}{c}\text { Establishing or maintaining appropriate interpersonal } \\
\text { relationships is not a priority }\end{array}$ \\
\hline Relation with others II & $\begin{array}{l}\text { Others are evaluated primarily in their immediate } \\
\text { ability to give care, comfort, and satisfaction }\end{array}$ & $\begin{array}{c}\text { They tend to be solitary, reserved, distant, } \\
\text { and appear insensitive }\end{array}$ \\
\hline Contents & Feelings, emotions, relations & $\begin{array}{l}\text { Manifest behavior and causality. } \\
\text { Constant and severe self-critical evaluation }\end{array}$ \\
\hline Attachment & Anxious, preoccupied attachment style & Avoidant attachment style \\
\hline Stressor related to depression & Separation, loss, grief rejection & Failure, humiliation, wounded self-esteem \\
\hline Content of depression & Sadness, loneliness, hopelessness & $\begin{array}{l}\text { Self-punishment, guilt, feelings of failure, } \\
\text { of being unworthy, low-grade }\end{array}$ \\
\hline Response to psychotherapy & $\begin{array}{l}\text { Gets worse with psychoanalysis. } \\
\text { Benefits from supportive-expressive therapy }\end{array}$ & $\begin{array}{l}\text { Benefits from psychoanalysis. } \\
\text { No response to supportive-expressive therapy } \\
\text { No response to short-term therapies }\end{array}$ \\
\hline Definition & Dependency & Self-critical perfectionism \\
\hline
\end{tabular}


525) -a notion closely connected with Blatt's. More specifically, the OPD system refers to the availability of mental functions for the regulation of the self and its relationships with internal and external objects.

The degree of availability or the limitations of an individual's functioning are described upon the basis of the level of structural integration of the function in question (OPD Task Force, 2008). These levels, within a dimensional continuum, are defined as high integration (level 1), moderate integration (level 2), low integration (level 3), and disintegration (level 4), depending on an individual's functioning level, that is, the availability of capabilities or vulnerabilities of the self and its object relationships. Further, the OPD system introduces four assessment dimensions (both for the self and the object), which are assessed separately to produce a total structure level score (OPD Task Force, 2008; Doering et al., 2014). The four dimensions are: percepction (self-perception and object-perception), regulation (self-regulation and regulation of object relationships), emotional communication (internal and external) and attachment (to internal objects and to external objects). Each of this dimensions have subdimensions that can be measured.

Even though the OPD system was developed as a diagnostic assessment measure for the therapist (or raters in research contexts), a self-rating questionnaire was recently created which covers all four structural dimensions (OPDStructure Questionnaire, OPD-SQ, Ehrenthal et al. 2012; Schauenburg et al. 2012). It is described in a later section.

The Millennium Scientific Initiatives (Millennium Nuclei on Psychological Intervention and Change in Depression and the Millennium Institute for Research in Depression and Personality, MIDAP) study depression and its connection with personality considering the multidimensionality of the notion of depression presented above, exploring the personality profiles that underlie depressive disorders and examining the predictive power of the distinctions advanced by Blatt (Blatt, 2004; Blatt, D'Afflitti \& Quinlan, 1976) and the underlying structural functioning of these constructs in order to propose specific psychotherapeutic treatments that are ideally suited to these dysfunctions (and not to descriptive diagnoses).

The general aim of this paper is to share the results of the Millennium Initiatives that have contributed to clinical psychotherapeutic thinking. Its first specific aim is to summarize results reported elsewhere that support the predictive value of introjective and anaclitic functioning (Part I), while its second specific aim is to report original data that account for the structural functioning of personality underlying these two constructs (Part II).

\section{Part I: results of the Millennium Scientific Initiatives: the predictive value of self-critical and dependent functioning}

Our multidimensional approach to depression consisted in studying it from a neurophysiological, psychological, and psychosocial perspective.
At a neurophysiological level, Silva, Jaramillo, Salazar, and Krause (2014) assessed 101 university students and found that the more self-critical (introjective) subjects, according to the DEQ, had higher levels of salival cortisol when exposed to an experimental situation that measured their response to the induction of interpersonal stress (Trier Social Stress Test, Kirschbaum, Pirke, \& Hellhammer, 1993) and reported less subjective anxiety when they answered the State-Trait Anxiety Inventory (STAI, Spielberger, Gorsuch, \& Luschene, 1970). This means that self-critical subjects show higher reactivity to physiological stress but do not feel (subjectively) stressed.

In another study on neurophysiological aspects, Rodríguez et al. (2016), using a sample of 91 undergraduate students, explored the relationship between dependent and self-critical functioning, on the one hand, and the emotional, cognitive, and social deficits associated with depressive symptomatology, on the other. In order to assess cognitive performance, they used a Stroop test (1935) and the Serial Reaction Time (SRT) test (Nissen \& Bullemer, 1987). To assess mentalization, they employed the "Reading the Mind in the Eyes" facial recognition test (RMET; Baron-Cohen, Wheelwright, Hill, Raste, \& Plumb, 2001). The researchers found that higher dependency scores on the DEQ scale were associated with longer reaction times on the Stroop test, while higher self-criticism levels in the DEQ were linked to fewer correct answers on the mentalization test of the RMET.

From a psychosocial perspective, Olhaberry et al. (2015) developed and implemented an attachment group counseling program (5 sessions) for 150 depressed pregnant women, with the aim of reducing maternal depression and improving future mother-child attachment. They found that, in general, the intervention reduced depression scores (BDI-I; Beck, Ward, Mendelson, Mock, \& Erbaugh, 1961); however, when separating patients with high dependency scores from those with high self-criticism scores, the depression scores of the latter did not decrease due to the intervention. Furthermore, they found that high selfcriticism was associated with higher avoidant and anxious attachment scores (according to the Experiences in Close Relationship Scale, ECR, Brennan, Clark \& Shaver, 1998); in contrast, high dependency scores were associated with higher anxious attachment scores.

From a psychological perspective and using a sample of 43 depressed outpatients, Dagnino et al. (2016, in press) reported similar findings: introjective patients (high self-criticism) showed anxiety and avoidant attachment, while anaclitic patients (high dependency) showed anxious attachment only (also according to the ECR, Brennan, Clark \& Shaver, 1998). Further, higher levels of self-criticism were associated with more depressive symptomatology at the beginning of psychotherapy according to the BDI-I (Beck et al., 1961), more likelihood to abandon the psychotherapeutic process, and less symptomatic change at the end of therapy. 
Finally, when studying psychotherapeutic processes, Valdés and Krause (2015), using the Therapeutic Activity Coding System (TACS-1.0) (Valdés, Tomicic, Pérez, \& Krause, 2010), analyzed patient and therapist speech during the session by identifying communicative actions (that is, how they say what they say) and the contents conveyed (that is, what is transmitted when speaking), noting that patients with anaclitic depression tended to resignify during change episodes (as expected), while those with introjective depression tended to resignify during stuck episodes.

Thus far, the studies described support the predictive value of the self-critical and dependent profiles: self-critical functioning was associated with more reactivity to stress, less subjective awareness of it, poorer performance in cognitive tasks, and less mentalization compared with dependent or control subjects. Patients with a self-critical profile who were receiving psychotherapy due to their depression displayed more symptoms at the start of the process than the rest of the patients, had higher dropout rates, and responded more weakly to psychological interventions. The profiles also predict different attachment styles and even differences in the therapeutic processes conducted. Considering that dependent patients, compared with self-critical ones, display more adherence and respond better to brief psychotherapy -as our results and the existing literature show (e.g. Blatt, 1992; Blatt \& Luyten, 2009a, 2009b) - it is self-critical depressive patients who constitute a treatment challenge. This issue was addressed in another article (not published yet) and will be revisited in the final discussion.

\section{Part II: personality structure and self-critical and dependent functioning}

The main aim of our line of research was to explore the differential personality functioning of depressive patients and subjects with self-critical and dependent styles. Clinical practice and research (e.g. Zimmermann et al., 2012) have shown that the worse an individual's structure in his/her personality functioning, the more symptomatology he/she will display; in this regard, our hypothesis is that the OPD will predict more depressive symptomatology in connection with poorer structural functioning (see below). With respect to introjective/anaclitic styles, the literature is contradictory (Blatt, 2008; Blatt \& Luyten, 2009a, 2009b), because even though Blatt states that dependent styles predict more severe pathology, he also notes the higher suicidality and poorer therapeutic prognosis in the case of introjective patients. For this reason, the present study, aimed at describing personality structure functioning is eminently exploratory.

For the study of personality functioning, we used the OPD Structure Questionnaire (OPD-SQ; Ehrenthal et al., 2012; Schauenburg et al., 2012), which defines the four dimensions which are described in depth in a later section.

Thus far, we had found that high self-criticism was as- sociated with less integrated structural functioning (Dagnino et al., 2015; de la Fuente et al., 2016).

These initial results encouraged us to study structural functioning in clinical samples (individuals seeking care at outpatient clinics) and nonclinical samples, with the aim of obtaining detailed information on capabilities/vulnerabilities provided by the OPD diagnosis, through an exploratory strategy. Our guiding questions were: How is structural functioning linked to depressive symptomatology? What are the characteristics of the structural functioning that underlies the self-critical style? What are the characteristics of the structural functioning that underlies the dependent style? Are any specific characteristics of structural functioning linked to the self-critical or the dependent style? The original results of this study are presented below.

\section{Materials and Methods}

\section{Participants}

A total of 296 individuals participated in this study. The total sample was formed by two subsamples: one clinical sample, which was recruited in two outpatient centers located in Santiago, and a nonclinical sample, recruited in a university in Santiago. The clinical sample consisted of 94 participants who contacted one of the centers seeking psychological care and who had been diagnosed with depression by their therapist. Patients under 18 , substance abusers, and individuals with psychotic symptoms were excluded from the study.

The nonclinical sample was formed by 108 university students. Participants who reported being under psychological treatment when the instruments were administered were excluded from the study. The data obtained from 94 participants were not considered because they did not answer all the questionnaires. Relative frequencies for gender and education levels in the total sample and the clinical and nonclinical sample are summarized in Table 2.

\section{Measures}

\section{Beck Depression Inventory}

The Beck Depression Inventory (BDI-I) (Beck, Ward, Mendelson, Mock \& Erbaugh, 1961), a self-report questionnaire for assessing depressive symptomatology, was used. The BDI-I has been translated into several languages and is extensively used all over the world and in primary care in Chile (Alvarado, Vega, Sangueza, \& Muñoz, 2005). The instrument consists of 21 items rated using a scale from 0 to 3 . It has an adequate level of internal consistency and is highly reliable, with an alpha coefficient estimated at 0.86 for clinical population and 0.81 for nonclinical population (Beck, Steer, \& Carbin, 1988). The Chilean version has been shown to be suitable for as- 
sessing depressive symptomatology, with an adequate level of internal consistency $(\alpha=.93)$.

\section{Depressive Experiences Questionnaire}

The Depressive Experiences Questionnaire (DEQ) (Blatt et al., 1976; Blatt, 1995; Zuroff, Quinlan, \& Blatt, 1990) was used to evaluate dependency and self-criticism, two key dimensions in the configuration of the introjective and anaclitic depressive styles. This instrument includes items that are representative of common experiences of individuals suffering from depression, without focusing on their depressive symptoms. The DEQ is a validated measure of these dimensions, and contains 66 items scored with a Likert scale ranging from 1 (strongly disagree) to 7 (strongly agree). The psychometric properties of the DEQ are satisfactory, with high estimated levels of internal consistency and test-retest reliability (Blatt et al., 1976; Zuroff et al., 1990). In this case, we used the version in Spanish adapted for Chile by Röst and Dagnino (2011).

\section{The Operationalized Psychodynamic Diagnosis Structure Self-rating Questionnaire}

The OPD-SQ comprises 95 items (Ehrenthal et al., 2012; Schauenburg et al., 2012) that assess eight structural dimensions. These are grouped into four basic functions (for the self and the object): i) perception, ii) regulation, iii) emotional communication, and iv) attachment (ability to establish bonds). Each scale is further divided into three specific abilities.

First, perception (self-perception and object-perception) refers to the ability to form a differentiated image of one's own self (self-perception), differentiating between affects (affect differentiation) and coherently maintain this self-image constantly over time (identity), forming a realistic picture of the other person (realistic object perception), which requires distinguishing between what is one's own and what is the other's (self-object differentiation), being able to see the object as a whole (OPD Taskforce, 2008).

Second, the capacity to regulate (self-regulation and regulation of object relationships) refers to the ability to experience oneself as the agent of one's own competent actions, and to derive self-confidence and self assurance from this experience of self-effectiveness (affect tolerance and regulation of self-esteem). In addition, it takes into account the ability to control one's own impulses or affects (impulse control). On the other hand, this dimension involves not only the protection of relationships from one's own impulses (protecting relationships), but also the safeguarding of one's own interests (balancing interests) and the ability to predict the reactions of others (anticipation) in response to one's own behavior (OPD Taskforce, 2008).

Third, emotional communication (internal and external communication) is the ability to have inner dialogues (experiencing affect) and understand oneself and the capacity to use fantasies (use of fantasies) and the body's self-experience (bodily self). It also concerns the ability to communicate affects to others (communicating affect) and be moved by the affects of others, as well as mutual understanding (establishing contact) and the use of empathy (empathy) (OPD Taskforce, 2008).

Fourth, attachment, (attachment to internal and external objects) refers to the ability to form emotional bonds with important others (capacity for attachment), develop internal images (internalization), and internalize positive aspects and therefore have these introjects available (use of introjects). On the other hand, it refers to the ability to detach from relationships, mourn (detaching from relationships), experience pro-social affects towards internal and external objects (variability of attachment), and seek and accept help (accepting help) (OPD Taskforce, 2008) (In italics the specific functions measured by the instrument).

Every item is rated using a five-point Likert scale that ranges from I disagree to I totally agree, with higher scores indicating less structural integration. The average of all the scales is an indicator of global structural functioning. Reliability studies conducted in Germany with 1110 subjects have reported internal consistency scores between $\alpha=.71$ and .91 for the subscales and $\alpha=.96$ for overall functioning in three different samples $(\mathrm{N}=734$ nonclinical participants, $\mathrm{N}=172$ outpatients, and $\mathrm{N}=204$ inpatients; Ehrenthal et al., 2012). The version used was translated by a team in Chile whose performance in the translation-retranslation process was satisfactory. Said process was supervised by the original authors of the instrument. A pilot study with 173 participants showed adequate internal consistency, both for its overall score and its subscales.

Table 2. Gender and education frequencies for the total, nonclinical, and clinical sample.

\begin{tabular}{lccc}
\hline & Total sample & Nonclinical sample & Clinical sample \\
\hline Gender (\% female) & 72.6 & 70.3 & 75.2 \\
\hline Education & & & 2.1 \\
Secondary school - incomplete (\%) & 1.0 & 0 & 28.5 \\
Secondary School - complete (\%) & 13.1 & 0 & 14.7 \\
Higher technical studies (\%) & 6.8 & 0 & 54.7 \\
University (\%) & 79.1 & 100 & \\
\hline
\end{tabular}




\section{Procedures}

In order to obtain a clinical sample, we contacted patients receiving care at two outpatient centers located in Santiago. Those who accepted to participate voluntarily filled in an informed consent form and completed the aforementioned instruments.

The individuals included in the nonclinical sample were recruited through an open call for participants - informed via email - and agreed to participate voluntarily, in exchange of a fee of approximately US\$20. Those who expressed their interest in participating read and signed the informed consent form. Afterwards, they completed the instruments described above along with a socio-demographic and health data form.

This study was approved by the Ethics Committee of Pontificia Universidad Católica de Chile's Faculty of Social Sciences, Protocol ID 160104007.

\section{Data analysis}

First, Pearson correlations were conducted considering the overall OPD score and subscale scores, depressive symptomatology (BDI), and the DEQ's self-criticism and dependency scores. In order to establish the significance of the differences observed between the self-criticism-total OPD correlation and the dependency-total OPD correlation, a difference test between paired correlations was conducted. Lastly, two linear regression models were calculated, using each of the OPD subscales as a predictor. The dependent variable in the first model was self-criticism, while dependency was used in the second. All analyses were carried out using R v 3.1.2 (R core team, 2014).

\section{Results}

First, bivariate correlations were performed to evaluate the association between depressive symptomatology (BDI) and self-criticism and dependency levels (DEQ), on the one hand, and the level of integration of the whole structure and that of each structural function (OPD), on the other (Table 3). Regarding the total OPD score, it was found to be positively and significantly related with depressive symptomatology $(r=.70, \mathrm{P}<.001)$ and the self- criticism ( $r=.66, \mathrm{P}<.001)$ and dependency scales $(r=.45$, $\mathrm{P}<.001)$. Therefore, the less integrated the structure, the higher the observed levels of depressive symptomatology, self-criticism, and dependency. Nevertheless, the correlation between self-criticism and OPD is significantly higher than that between dependency and OPD $(t=-3.4$, $\mathrm{P}<.001)$.

Examining the OPD subscales (Table 3) revealed that dependency is positively and significantly correlated with all structural functions. These correlations have magnitudes ranging from mid to high. Thus, it is observed that a higher dependency level is associated with less integration of structural functions. As for self-criticism, positive and significant correlations were also observed with structural functions. In this case, all correlations are high, which indicates that more self-criticism entails less integration of structural functions.

In order to determine which structural functions are better predictors of each depressive experience, two linear regressions were performed with self-criticism and dependency as dependent variables and each of the structural functions as predictors (Table 4). In the case of self-criticism, it was observed that object-perception $(\beta=0.26, \mathrm{P}=.033)$ and attachment to internal objects $(\beta=0.34, \mathrm{P}=.002)$ are significant predictors (Table 2). On the other hand, the significant predictors of dependency are self-perception $(\beta=0.32, \mathrm{P}=.033)$, self-regulation $(\beta=0.44, \mathrm{P}=.003)$, and attachment to external objects $(\beta=0.25, \mathrm{P}=.045)$.

\section{Discussion}

In the present study, we observed, as expected, that personality structures with lower levels of integration according to the OPD system are associated with more symptomatology. On the other hand, more self-critical functioning is associated with more depressive symptomatology and less integration of structural functioning: more specifically, more self-critical functioning is associated with more vulnerability in the OPD dimensions Regulation of object relationships and Attachment to internal objects. Dependent functioning, in contrast, is associated with less integrated functioning in the capabilities

Table 3. Bivariate correlations between depressive symptomatology, depressive experiences, and structural functions.

\begin{tabular}{|c|c|c|c|c|c|c|c|c|c|}
\hline & OPD total & $\begin{array}{c}\text { Self- } \\
\text { perception }\end{array}$ & $\begin{array}{c}\text { Object } \\
\text { perception }\end{array}$ & $\begin{array}{c}\text { Self- } \\
\text { regulation }\end{array}$ & $\begin{array}{l}\text { Regulation of } \\
\text { object } \\
\text { relationships }\end{array}$ & $\begin{array}{l}\text { Emotional } \\
\text { communication } \\
\text { (internal) }\end{array}$ & $\begin{array}{c}\text { Emotional } \\
\text { communication } \\
\text { (external) }\end{array}$ & $\begin{array}{c}\text { Attachment } \\
\text { to } \\
\text { internal } \\
\text { objects }\end{array}$ & $\begin{array}{c}\text { Attachment } \\
\text { to } \\
\text { external } \\
\text { objects }\end{array}$ \\
\hline BDI symptomatology & $y .70 * * *$ & $.66 * * *$ & $.59 * * *$ & $.68 * * *$ & $.53 * * *$ & $.62 * * *$ & $.54 * * *$ & $.63 * * *$ & $.54 * * *$ \\
\hline Self-criticism & $.66^{* * *}$ & $.62 * * *$ & $.60 * * *$ & $.59 * * *$ & $.57 * * *$ & $.52 * * *$ & $.50 * * *$ & $.65 * * *$ & $.49 * * *$ \\
\hline Dependency & $.45 * * *$ & $.46^{* * *}$ & $.35 * * *$ & $.49 * * *$ & $.36 * * *$ & $.29 * * *$ & $.36 * * *$ & $.35 * * *$ & $.40 * * *$ \\
\hline
\end{tabular}

OPD, Operationalized Psychodynamic Diagnosis; BDI, Beck Depression Inventory. ***P<.001. 
of self-perception, self-regulation, and attachment to external objects.

Our finding that patients who are more vulnerable in terms of personality structure display more symptoms is consistent with clinical experience and previous research (Ehrenthal et al., 2012; Scahuenburg et al., 2012). If we consider the structural capabilities proposed by the OPD system, we can expect subjects who are vulnerable in functions such as self-regulation (which includes the regulation of self-esteem, emotions, and impulses), attachment to internal objects (which includes the use of introjects to soothe themselves), and self-perception and internal communication (which allow them to identify the mechanisms and emotions that underlie their symptoms) to experience more psychic suffering and symptoms. The relationship between levels of self-criticism and depressive symptoms is consistent with the findings published by other authors (McGrath et al., 2012; Luyten et al., 2012; Luyten \& Blatt, 2011).

The results described in this article replicate the aforementioned results of the Millennium Initiative (Part I of this paper), which showed that self-critical functioning predicts more symptomatology and poorer structural functioning. These results indirectly contradict Blatt's notion (2004) that introjective depression is at a more advanced level of psychological development (p. 48), which should result in a better structural level. Nevertheless, Blatt himself has referred to the destructiveness of self-critical perfectionism (1995); also, different authors have discussed the pathogenic power of self-critical functioning along with the high suicidality of these patients and the difficulties involved in managing and treating them (Blatt \& Shahar, 2004; Layne, Porcerelli \& Shahar, 2003; Blatt, Quinlan, Pilkonis, \& Shea, 1995; Marshall, Zuroff, Mcbride, \& Bagby, 2008; Leadbeater, Blatt, \& Quinlan, 1995; Blatt, 1995; Blatt et al., 1982).

Our findings connected with the specific vulnerabili-

Table 4. Linear Regression Models of Self-Criticism (Model 1) and Dependency (Model 2) in each structural function.

\begin{tabular}{lcc}
\hline & $\begin{array}{c}\text { Model 1: } \\
\text { self-criticism }\end{array}$ & $\begin{array}{c}\text { Model 2: } \\
\text { dependency }\end{array}$ \\
\hline Coefficients & $-0.16^{*}$ & $-0.50^{* * *}$ \\
Intercept & 0.22 & $0.32^{*}$ \\
Self-perception & 0.10 & -0.15 \\
Object perception & 0.05 & $0.44^{* *}$ \\
Self-regulation & $0.26^{*}$ & 0.05 \\
Regulation of object relationships & -0.03 & -0.20 \\
Internal communication & -0.17 & 0.02 \\
External communication & $0.34 * *$ & -0.18 \\
Attachment (internal) & 0.04 & $0.25 *$ \\
Attachment (external) & & \\
\hline Model fit & .44 & .25 \\
$\mathrm{R}^{2}$ & $21.02 * * *$ & $9.37^{* * *}$ \\
$\mathrm{~F}_{(8,195)}$ & & \\
\hline
\end{tabular}

$* \mathrm{P}<.05 ; * * \mathrm{P}<.01 ; * * * \mathrm{P}<.001$. ties in the personality structure of these subjects are consistent with self-critical functioning: the regulation of object relationships involves the ability to protect the relationship, balance one's interests with respect to those of others, and anticipate other people's reactions to one's actions. All this entails seeing the other, which can be out of the reach of subjects with self-critical (introjective) functioning given their inward-looking focus on self-definition and independence. The same is true of the vulnerability displayed by these subjects in terms of their ability to develop attachments to internal objects: possibly, a high level of self-criticism reflects the absence of good and soothing internal objects capable of silencing selfcritical voices.

Our findings regarding dependent functioning are consistent with structural vulnerabilities underlying the anaclitic style: this functioning is associated with vulnerabilities in terms of self-perception capabilities (self-reflection, affective differentiation, and identity), because these individuals are more interested in their relationships with others than in looking at and defining themselves. Likewise, vulnerabilities with respect to their attachment to external objects precisely refer to difficulties establishing mature attachments, receiving and requesting help in a mature way (without clinging to others), and separating from others and mourning. Even though it is not yet clear whether poor self-regulation in dependent functioning is more heavily affected by the dysregulation of self-esteem, impulses, or affect tolerance, our findings entail interesting therapeutic consequences that we will discuss below.

With respect to psychotherapeutic strategies, the OPD system (OPD Task Force, 2008) indicates that the basic strategic decision in dynamic psychotherapies is whether therapeutic work will focus on treating the conflict with interpretive and expressive techniques, on treating the structure with techniques intended to support the relationship and the structural functions of the self, which has also been labeled structure-oriented therapy (Rudolf, 2013), or on treating both in an expressive-supportive (ES) continuum. Considering that we are more interested in examining the structural functioning of these patients, and bearing in mind that dynamic therapists are more familiar with interpretive techniques, we will focus on discussing psychotherapy with reference to the treatment of structural dysfunctions/vulnerabilities.

The previous results of the Millennium program, described in Part I of the present paper, reveal that patients with dependent functioning benefit more from therapies and are less likely to abandon them than those with selfcritical functioning. Probably, for these patients, the therapeutic alliance is based upon dependency - which is often a problem in many nontherapeutic interpersonal relationships. These patients' hunger for attachment probably makes them more permeable to interventions, which explains their ability to benefit from different therapies and 
interventions as shown in Part I. We believe that these patients' vulnerabilities in the sphere of self-perception could be addressed with mentalization techniques (Luyten, Fonagy, Lemma \& Target, 2012); in this regard, structure-oriented psychotherapy (Rudolf, 2013) has made several interesting contributions, many of which also involve mentalization. In this type of therapy, and depending on the structural level examined, the therapist can adopt a parental attitude in order to provide support within his/her relationship with the patient; in addition, he/she can offer him/herself as an identification figure, sharing thoughts and feelings with the patient in a gradual way while also expressing his/her differences with the patient. Thus, self-reflection, affective differentiation, and identity could eventually be respectively addressed in connection with vulnerabilities in the sphere of self-perception. With respect to the attachment to external objects dysfunction/vulnerability, as pointed out above, dependency can be a means for therapeutic intervention; however, based on the parental attitude proposed by Rudolf (2013), it would be possible to regulate the distance established with a patient who clings to the therapist, while also allowing him/her to experience separations that do not entail abandonment, and later on, towards the end of the therapy, letting him/her have an experience of mourning, although many of these patients with a more fragile structure could need the therapist to become a real object within the context of a corrective emotional experience (Alexander \& French, 1946; Elliott, Bohart, Watson, \& Greenberg, 2001; Rudolf, 2013). In this way, the therapy ends but the relationship does not, and the therapist remains available for the patient to come to him/her. Lastly, in anaclitic functioning, addressing the self-regulation vulnerability/dysfunction from the perspective of structure-oriented psychotherapy involves the construction of an observing self, similarly to what mentalization therapy proposes. From this perspective, the therapist must stand shoulder to shoulder with the patient, looking down from the hill, and observe his/her functioning with the aim of developing a distance and providing insights about his/her functioning (and not about the meaning of his/her behavior, which is recommended for patients with a good structural functioning), so that he/she can become aware of his/her patterns and thus be able to tackle emotional storms (affective regulation) and manage his/her impulses before reaching the point of no return. The regulation of self-esteem could be addressed through a realistic assessment of achievements and failures based on the parental relationship presented above.

Regarding self-critical functioning, a number of empirical and theoretical studies have referred to the difficulties involved in treating these patients (e.g. Blatt et al., 1995; Chang, 2008; Dinger et al., 2014; Kannan \& Levitt, 2013). There is consensus among therapists that these patients hinder the construction of the therapeutic alliance and that it is already hard for them to establish attachments. In our opinion, this reflects the vulnerability involving regulation of object relationships, which makes it difficult for the patient to see the therapist. This not only would require constructing, caring for, permanently monitoring the therapeutic alliance, and paying attention to its ruptures and repairs (Bateman \& Fonagy, 2012; Safran \& Muran, 2000); in addition, as noted above, it would be necessary to gradually become a real object, with thoughts, feelings, and emotions. Self-criticism appears rapidly and precociously in the therapy. It should be directly tackled as a dysfunction, that is, we should focus our attention on the process of selfcriticism (Kannan \& Levitt, 2013), or, in terms of structureoriented therapy, it would be necessary to look at that self-critical functioning from the hill. As our results showed, we also regard self-criticism as a dysfunction in attachments to internal objects. Therefore, by means of the strategy of becoming real objects to be internalized through our interaction with the patient, our attitude, and the holding function that this could exert on implicit memory (Rudolf, 2013), we could have an indirect impact on self-critical dysfunction during the process.

\section{Conclusions}

Finally, our findings support the notion that an adaptive indication (Thomä \& Kächele, 1985), i.e. a personalized treatment (Hasler, 2010), is needed; that is, we should address the specific dysfunction of each patient (van Praag, 2010). This perspective allows us to advance, in line with other authors (e.g. Blatt, 1992; Blatt \& Luyten, 2009a, 2009b; Blatt et al., 1995), the view that within certain boundaries, psychotherapeutic prognosis does not depend on the descriptive diagnosis arrived at (depression or personality disorder), but on obstacles and facilitators associated with each type of functioning (anaclitic, introjective) which are in turn an expression of specific structural vulnerabilities/dysfunctions.

Even though we think that it is necessary to explore whether these results can be replicated with larger samples, while also assessing the role of intrapsychic conflict (OPD Task Force, 2008) in the functioning of these patients, we consider that our work supports the provision of a personalized type of psychotherapy that takes into account each patient's individuality beyond diagnostic categories.

\section{References}

Alexander, F., French, T. (1946) Psychoanalytic therapy: principles and application. New York: Ronald Press.

Alvarado, R., Vega, J., Sanhueza, G., \& Muñoz, M.G. (2005). Evaluación del Programa para la Detección, Diagnóstico y Tratamiento Integral de la Depresión en atención primaria, en Chile [Evaluation of the Program for Detection, Diagnosis and Treatment of Depression in primary care in Chile]. Revista Panamericana de Salud Pública, 18(4-5), 278-286. 
Baron-Cohen, S., Wheelwright, S., Hill, J., Raste, Y., \& Plumb, I. (2001). The "Reading the Mind in the Eyes" test revised version: a study with normal adults, and adults with asperger syndrome or high-functioning autism. Journal of Child Psychology and Psychiatry, 42 (2), 241-251.

Bateman, A., Fonagy, P. (eds) (2012) Handbook of mentalizing in mental health practice. Arlington: American Psychiatric Publishing, Inc.

Beck, A., Steer, A., \& Carbin, M. (1988) Psychometric properties of the Beck Depression Inventory: twenty-five years of evaluation. Clinical Psychology Review, 8 (1) 77-100. doi:10.1016/0272-7358(88)90050-5

Beck, A.T., Ward, C.H., Mendelson, M., Mock, J.E., \& Erbaugh, J. (1961). An inventory of measuring depression. Archives of General Psychiatry, 4, 561-585. http://dx.doi.org/10.1001/ archpsyc.1961.01710120031004

Blatt, S.J. (1992). The differential effect of psychotherapy and psychoanalysis with anaclitic and introjective patients: the Menninger Psychotherapy Research Project revisited. Journal of the American Psychoanalytic Association, 40, 691-724.

Blatt, S.J. (1995). The destructiveness of perfectionism: implications for treatment of depression. American Psychologist, 50, 1003-1020.

Blatt, S.J. (2004) Experiences of depression: theoretical, clinical and research perspectives. Washington, DC: American Psychological Association.

Blatt, S.J. (2008) Two primary configurations of psychopathology. In Blatt, S. (Ed.) Polarities of experiences: relatedness and self-definition in personality development, psychopathology and the therapeutic process (pp. 234-245). Washington, DC: American Psychological Association.

Blatt, S.J., D’Afflitti, J.P., \& Quinlan, D.M. (1976). Experiences of depression in normal young adults. Journal of Abnormal Psychology, 85, 383-389.

Blatt, S.J., \& Luyten, P. (2009a) A structural-developmental psychodynamic approach to psychopathology: two polarities of experiences across the life span. Development and Psychopathology, 21, 793-814.

Blatt, S.J., \& Luyten, P. (2009b). Depression as an evolutionary conserved mechanism to terminate separation-distress: only part of the biopsychosocial story? NeuroPsychoanalysis, 11, 52-61.

Blatt, S.J., \& Maroudas, C. (1992). Convergence of psychoanalytic and cognitive behavioral theories of depression. Psychoanalytic Psychology 9, 157-190.

Blatt, S.J., Quinlan, D., Chevron E., McDonald, C., \& Zuroff, D. (1982). Dependency and self criticism: psychological dimensions of depression. Journal of Consulting and Clinical Psychology 50 (1), 113-124. http://dx.doi.org/10.1037/0022006X.50.1.113

Blatt, S.J., Quinlan, D.M., Pilkonis, P.A., \& Shea, T. (1995). Impact of perfectionism and need for approval on the brief treatment of depression: the National Institute of Mental Health Treatment of Depression Collaborative Research Program revisited. Journal of Consulting and Clinical Psychology, 63, 125-132.

Blatt, S.J., \& Shahar, G. (2004). Psychoanalysis: for what, with whom, and how? A comparison with psychotherapy. Journal of the American Psychoanalytic Association, 52, 393-447.

Blatt, S.J., \& Shichman, S. (1983). Two primary configurations of psychopathology. Psychoanalysis and Contemporary Thought, 6, 187-254.

Blatt, S.J., Zohar, A., Quinlan, D., Zuroff, D., \& Mongrain, M. (1995) Subscales within the dependency factor of the depressive experiences questionnaire. Journal of Personality
Assessment, 64 (2) 319-339. doi: 10.1207/s15327752 jpa6402_11

Blatt, S.J., \& Zuroff, D.C. (1992). Interpersonal relatedness and self-definition: two prototypes for depression. Clinical Psychology Review, 12, 527-562.

Brennan, K.A., Clark, C.L., \& Shaver, P.R. (1998). Self-report measurement of adult romantic attachment: An integrative overview. In J.A. Simpson \& W.S. Rholes (Eds.), Attachment theory and close relationships (pp. 46-76). New York: Guilford Press.

Chang, E.C. (2008). Self-criticism and self-enhancement: theory, research and clinical implications. Washington, DC: American Psychological Association. doi:10.1037/11624-000

Dagnino, P. (2015) Structural vulnerabilities of depression. In Millennium Nucleus Research Program "Psychological Intervention and Change in Depression" meeting. Santiago, Chile: Universidad de Chile.

de la Fuente, I., Harismendi, A., Gallardo, A.M., Dagnino, P., Gómez-Barris, E., Valdes, C., \& de la Parra, G. (in press). Dimensiones de la experiencia depresiva y funcionamiento estructural: ¿qué hay a la base de la heterogeneidad de la depresión? [Depressive experiences dimensions and structural functioning: what are the underlying factors of depression heterogeneity?]. Revista Argentina de Clínica Psicológica.

Dinger, U., Barrett, M.S., Zimmermann, J., Schauenburg, H., Wright, A.G.C., Renner, F., ... Barber, J.P. (2014). Interpersonal problems, dependency, and self-criticism in major depressive disorder. Journal of Clinical Psychology, O(0), 1-12. http://doi.org/10.1002/jclp.22120

Doering, S., Burgmer, M., Heuft, G., Menke, D., Bäumer, B., Lübking, M., Feldmann M., Schneider, G. (2014). Assessment of personality functioning: validity of the operationalized psychodynamic diagnosis axis IV (Structure). Psychopathology, 47(3), 185-193. doi:10.1159/000355062

Ehrenthal, J.C., Dinger, U., Horsch, L., Komo-Lang, M., Klinkerfuss, M., Grande, T., \& Schauenburg, H. (2012). Der OPD-Strukturfragebogen: Erste Ergebnisse zu Reliabilität und Validität [The OPD Structure Questionnaire (OPD-SQ): First results on reliability and validity]. Psychotherapie Psychosomatik Medizinische Psychologie, 62(1), 25-32. doi:10.1055/s-0031- 1295481

Elliott, R., Bohart, A.C., Watson, J.C., \& Greenberg, L.S. (2001). Empathy. Psychotherapy (Chic) 48(1), 43-49. doi: 10.1037/ a0022187

Hasler, G. (2010). Forum: fisiopatologia de la depresion: ¿tenemos alguna evidencia solida de interes para los clinicos? World Psychiatry, 9, 155-161.

Kannan, D., \& Levitt, H. (2013) A review of self-criticism in psychotherapy. Journal of Psychotherapy Integration. 23(2) 166-178. http://dx.doi.org/10.1037/a0032355

Kirschbaum, C., Pirke, K.-M., \& Hellhammer, D.H. (1993). The 'Trier Social Stress Test'. A tool for investigating psychobiological stress responses in a laboratory setting. Neuropsychobiology, 28 (1-2), 76-81.

Laska K.M, Gurman, A.S, Wampold, B.E. (2014) Expanding the lens of evidence-based practice in psychotherapy: a common factors perspective. Psychotherapy, 51, 467-481.

Layne, G., Porcerelli, G., \& Shahar, G. (2006). Psychotherapy of self-criticism in a woman with mixed anaclitic-introjective depression. Clinical Case Studies, 5, 421-436. doi: $10.1177 / 1534650106290370$

Leadbeater, B.J, Blatt, S.J, Quinlan, D.M. (1995). Gender-linked vulnerabilities to depressive symptoms, stress, and problem behaviors in adolescents. Journal of Research on Adolescence, 5, 1-29. 
Luyten, P., \& Blatt, S.J. (2007). Looking back towards the future: is it time to change the DSM approach to psychiatric disorders? The case of depression. Psychiatry, 70 (2), 85-99.

Luyten, P., \& Blatt, S.J. (2011). Psychodynamic approaches of depression: Whither shall we go? Psychiatry: Interpersonal and Biological Processes, 74, 1-3. doi:10.1521/psyc.2011. 74.1.1

Luyten, P., Fonagy, P., Lemma, A., \& Target, M. (2012) Depression (pp. 385-417). In Bateman, A., Fonagy, P. (Eds.) Handbook of mentalizing in mental health practice. Wahington, DC: American Psychiatric Publishing, Inc.

Marshall, M.B.M., Zuroff, D.D.C., Mcbride, C., \& Bagby, R.M. (2008). Self-criticism predicts differential response to treatment for major depression. Journal of Clinical Psychology, 64(3), 231-244. http://doi.org/10.1002/jclp

McGrath, D.S., Sherry, S.B., Stewart, S.H., Mushquash, A., Allen, S., Nealis, L., \& Sherry, D. (2012). Reciprocal relations between self-critical perfectionism and depressive symptoms: evidence from a short-term, four-wave longitudinal study. Canadian Journal of Behavioral Science, 44 (3), 169-181.

Nissen, M. y Bullemer, P. (1987). Attentional requirements of learning: evidence from performance measures. Cognitive Psychology, 19 (1), 1-32.

Olhaberry, M., Mena, C., Zapata, J., Miranda, A., Romero, M., \& Sieverson, C. (2015) Terapia de interacción guiada en díadas madre-bebé con sintomatología depresiva materna en el embarazo: un estudio piloto. [Guided Interaction Therapy in mother-baby dyads with maternal depressive symptomatology in pregnancy: a pilot study]. Summa Psicológica UST, 12 (2) 63-74.

OPD Taskforce (2008). Operationalized Psychodynamic Diagnostics OPD-2: manual of diagnosis and treatment planning. Cambridge, MA: Hogrefe.

R Core Team (2014). R: a language and environment for statistical computing. Vienna, Austria: R Foundation for Statistical Computing. Available from: http:/www.R-project.org/

Rodríguez, E., Ruiz, J.C., Valdés, C., Reinel, M., Díaz, M., Flores, J., Crempien, C., Leighton, C., ..., \& Tomicic, A., (2016) Estilos de personalidad dependiente y autocrítico: desempeño cognitivo y sintomatología depresiva [Dependent and self-critical personality styles: Cognitive performance and depressive symptomatology]. Revista Latinoamericana de Psicología (in press), http://dx.doi. org/10.1016/j.rlp.2016.09.005

Rost, R., \& Dagnino, P. (2011). Traducción a Chile del Depressive Experience Questionnaire (DEQ) [Chilean translation of the Depressive Experiences Questionnaire]. Santiago, Chile: Pontificia Universidad Catolica de Chile.
Rudolf, G. (2013). Strukturbezogene Psychotherapie. Stuttgart: Schattauer.

Safran, J.D., \& Muran, J.C. (2000). Negotiating the therapeutic alliance: a relational treatment guide. New York, NY: Guilford Press.

Schauenburg, H., Dinger, U., Komo-Lang, M., Klinkerfuss, M., Horsch, L., Grande, T., \& Ehrenthal, J.C. (2012). Der OPD Strukturfragebogen [The OPD structure questionnaire] (pp. 284-307). In S. Döring \& S. Hörz (Eds.), Handbuch der Strukturdiagnostik. Stuttgart: Schattauer.

Silva, J., Jaramillo, K., Salazar, L., \& Krause, M. (2014). Interpersonal stress and the polarities of experience: Effects on the psychophysiological responses and in the bias associated to the differential reinforcement of a behavioural task. Presented at 45th International Annual Meeting de la Society for Psychotherapy Research, Copenhagen, Denmark.

Spielberger, C.D., Gorsuch, R., \& Luschene, R. (1970). Manual for the state-trait anxiety inventory. Palo Alto, CA: Consulting Psychologist.

Stroop, J.R. (1935). Studies of interference in serial verbal reactions. Journal of Experimental Psychology, 18 (6), 643-662.

Thoma, H., \& Kachele, H. (1987). Psychoanalytic practice: Vol. 1. Principles. New York: Springer-Verlag.

Valdés, N., \& Krause, M. (2015). Verbal expressions used by anaclitic and introjective patients with depressive symptomatology: analysis of change and stuck episodes within therapeutic sessions. Clínica y Salud, 26(2), 103-119.

Valdés, N., Tomicic, A., Pérez, J.C., \& Krause, M. (2010). Sistema de Codificación de la Actividad Terapéutica (SCAT1.0): Dimensiones y categorías de las acciones comunicacionales de pacientes y psicoterapeutas. Revista Argentina de Clínica Psicológica, 19 (2), 117-129.

Van Praag, H.M. (2010). No functional psychopharmacology without functional psychopathology. Acta Psychiatrica Scandinavica, 122(6), 438-439. http://doi.org/10.1111/ j.1600-0447.2010.01629.x

Wampold, B.E. (2001). The great psychotherapy debate. Models, methods and findings. Mahwah, NJ: Erlbaum.

Zimmermann, J., Ehrenthal, J.C., Cierpka, M., Schauenburg, H., Doering, S., \& Benecke, C. (2012). Assessing the level of structural integration using operationalized psychodynamic diagnosis (OPD): implications for DSM-5. Journal of Personality Assessment, 94(5), 522-532. http://doi.org/10.1080/ 00223891.2012 .700664

Zuroff, D., Quinlan, D., \& Blatt, S.J. (1990). Psychometric properties of the Depressive Experiences Questionnaire in a college population. Journal of Personality Assessment, 55(1-2), 65-72. doi:10.1080/00223891.1990.9674047 